\title{
Review of the Individual and Organizational Factors Related to Human Resource Empowerment and Designing an Optimal Model to Promote Manifestations of Productivity
}

\author{
Rouhollah Nasiri' ${ }^{1}$, Ali Mollahosseini ${ }^{2, *}$, Sanjar Salajegheh ${ }^{3}$, Ayyub Sheikhy $^{4}$ \\ ${ }^{1} \mathrm{PhD}$ Student of Public Administration, Department of Management, Faculty of Literature and Humanities, \\ Kerman Branch, Islamic Azad University, Kerman , Iran \\ ${ }^{2}$ Full Professor, Department of management, Faculty of Management and Economics, University of Shahid \\ Bahonar, Kerman, Iran \\ ${ }^{3}$ Assistant Professor, Department of management, Faculty of Literature and Humanities, Kerman Branch, \\ Islamic Azad University, Kerman, Iran \\ ${ }^{4}$ Assistant Professor, Department of Statistics, Faculty of Mathematics and Computer, University of Shahid \\ Bahonar, Kerman, Iran
}

\section{Keywords:}

Empowerment, personal factors, organizational factors, effects of productivity

\section{Received}

09 May 2016

Received in revised form 01 October 2016

Accepted

24 October 2016

Correspondence:

a_mollahosseini@yahoo.com

\section{AbStract}

Human resources number of important factor and based organizational. Preparation this resource for faced with changes is of particular importance and of organization must in each mission allocated most capital, time and program. The solution to this problem, many organizations have recognized empowerment programs and tried to provide ground for nurturing staff. The relationship between individual and organizational factors in the institute of communications and information technology, the relationship between psychological empowerment responsibilities and not licensed, but the relationship between self-esteem, creativity and internal locus of control and psychological empowerment is confirmed. Relations between all factors include: clarity to goals, access to information, and access to resources, training and the provision of treatment with psychological empowerment is confirmed. Moreover, the relationship between psychological empowerment of human resources productivity showed the effects of lateral relations between all dimension of (including: significance, suitability, effectiveness, autonomy and trust) the effects of productivity is confirmed. 


\section{Introduction}

Now construct of human resources involved in the management process to achieve higher organizational performance and create competitive advantage for organization is essential.

The empowerment is inevitable. Quinn and Spreitzer (1997) argue that empowerment. Can give competitive advantage to the organization and empowerment of many good managers know, but most organizations have experienced difficulties in this implementation. WHETTEN and CAMERON (1998) states that by empowering employees, managers Brayer are actually multiply your effectiveness. While most managers know that they must be implemented empowerment skills, but the real management rarely done today. In the process of empowerment some factors have an influential role that some of these factors are as follows: of the goals authority in the organization, job enrichment, main tailing staff morale and skills development.

Established trust, cooperation and team work starting up the information, knowledge skills and job. Employee empowerment has large following. On the results of the implementation of the empowerment of organization, can be cited of follows:

Provide customer satisfaction, in line with market requirements, reduce operating costs and increase profits in the market, continual improvement and increased productivity, increased job satisfaction, increased sense of belonging, (SAJADI and OMIDVARI, 1386:67-66)

Institute of information and communication Technology (Telecommunications research center). Iran, one of the oldest research authority in HVZ. Fava is the main mission of the institute of institutionalizing and promoting the growth of knowledge, Technology and innovation in line with the countries intellectual preparation priorities specified in the statutes ordinances and documents country. Therefore, this study tries to answer the basic question that it is appropriate that an model factors related to the empowerment of human resources and information Technology (EFA) in which their productivity is therefore productivity effects.

In other words, this study seeks to evaluate which factors (individual, organizational, environmental and Technology). Related to empowerment and human resources what are the institute, the impact on their productivity effects creates?

\section{Literature}

Empowerment in management was introduced since the mid- $20^{\text {th }}$ century and formation of humanistic relationships towards increasing the humanistic conditions of labor (Jahanian, 2014). In this paper empowerment is introduced as the participation of the front line employees of the organization in four key areas of information, knowledge, reward and power. Consider empowerment as encouraging people to participate in decisions that are effective on their activities (Kakar, Raziq, \& Khan, 2015). In this way, many opportunities are provided for people, so that they show that they can create and fulfill great ideas (Tallon, Pinsonneault, 2011). However, empowerment may be considered including all the methods and measures that can affect the employees' attitude and behavior and help them to make the best decisions regarding the conditions of the organization and lead the organization toward the productivity through creativity in the form of team working. As it can be perceived from the definition of empowerment, competency describes a potentials that all people should possess in order to 
leverage for performance development. Moreover, in this definition, leverage introduces competency in practice (Humborstad, Perry, 2011).

In the psychological literature, power and control are used to describe the state of belief individual's internal motivation or expectation. For example, the individual is considered to have the need for power (Pando-Garcia, Periañez-Cañadillas, Charterina, 2016). In another word, he has the internal need to influence and control others. Power and control have drawn many psychologists' attention. Their studies include internal/external control, acquisition, and the main/secondary control. Individual's power needs will be met when they perceive that they have power or they believe they can adequately handle life events, situations or people attached to them. On the other hand, when the individual feels that power is very low, or they think they cannot handle the physical or social requirements that are raised by the environment, their power needs will not be met. Under the perspective of this research, power is related to an inner self-determining demand or a belief in individual self-efficacy (Dehaghani, Abbasi, 2017). Empowerment leadership behaviors from this perspective include any management decision or technology that can improve employee's inner level of motivation by enhancing his self-determining demand or self-efficiency (Yazdani, Yaghoubi, Giri, 2011). Thomas believed that empowerment was an improvement on the level of intrinsic motivation, and proposed the concept of "psychological empowerment" (Podsakoff, MacKenzie, \& Podsakoff, 2016). Spritzer explained employees' perception of power as the four aspects of employee's perception of work meaning, self-efficacy, autonomy and influence (Shih, Lai, \& Cheng, 2011).

According to social exchange theory, power is a concept that can reflect social concept. It represents the interdependent social function and the asymmetric control of resources and results in the context of a particular situation and social relations (Tschannen-Moran, \& Gareis, 2015). This definition implies two characteristics of power: controlling others and be independent of others in order to achieve their goals. Power works as a control mechanism. The one who owns power can drive others to help them achieve their goals. In another word, power is the ability not influenced by others. A person will be subject to others without power and he will be relatively free with power. Power source can be the individual's ability to provide valuable resources to the organization. It can also be his position in the organization structure, professional skills and opportunity to access to specific knowledge or information, etc. From this perspective, empowerment is a kind of resource allocation strategy that can reduce the dependence on high power. The empowerment leadership behavior can be defined as a series of management practices, including decentralization, participation, information sharing and training.

It was found that trust was the basis of empowerment leadership behavior (Dong, Liao, Chuang, Zhou, \& Campbell, 2015). Scholar thought that leader's trust degree in subordinate's performance and integrity can positively predict empowerment leadership behavior which is moderated by responsibility of the big five personality (Ibrahim, 2015). Researcher found that leader's cognitive trust and emotional trust in the subordinate are both helpful to increase the empowerment leadership behavior, in which cognitive trust has the greatest influence on the decision-making participation dimension of empowerment behavior and emotional trust has the greatest influence on information sharing dimension and coach dimension of empowerment behavior (Law, Buhalis, \& Cobanoglu, 2014). 
There are two approaches of structural-social and psychological in classic empowerment. The basis for structural-social approach toward the empowerment is based on the idea of sharing the power among the higher and lower levels with the aim of sharing the organizational levels in the related decisions and the psychological approach refers to a set of psychological statuses required by the employees that is essential in order to provide more responsibility and control in them. This approach describes that how the employees experience their job and what is their perceptions regarding their related roles in the organization (Jahanian, 2014).

Information technology includes a wide range of media and new methods that connects people and informatics systems together same as voicemail, E-mail, conferences, voice and video conferences, internet, intranet and local networks of the organizations, phones, fax devices (Madison, \& Denise, 2015). Nowadays, organizations consider information technology as a tool that help them develop the performance of their employees or adjusting to the changes. But, these organizations should encourage and persuade their employees in using the technology in line with the speed of technology changes and transformations, so that the performance of their employees become more effective and efficient regarding the education and profession level (Goetsch \& Davis, 2015).

\section{Research goals}

The most important aim of this study was to investigate and explain the factors related to the empowerment of human resources and provide the optimum modeling line with productivity effects of the following specific objectives are followed.

Explaining individual level factors related to empowerment institute of communication and information Technology.

Explaining the organizational level factors related to the empowerment institute of communication and information Technology.

Role of human resources empowerment institute consequences of ICT on productivity effects.

\section{Research questions}

For the purpose of this research was to study following questions can be expressed as:

- What are the personal factors contributing to the empowerment of human resources in research EFA?

- What are the organizational factors related to the empowerment of human resources in research EFA?

- In personal factors and empowering human resources in research EFA there?

- Any relationship between organizational factors and empowering human resources in research in EFA there?

- Any difference between empowerment and productivity aspects of human resources in research EFA there?

\section{Conceptual model}

According to the study, which examines the relationship between personal factors (self-esteem, responsibility, creativity, internal locus of control) and organizations (clarity of goals, access to 
information, bonuses, performance based logistics, modeling, organizational support, access to resources, job training, provide feedback) on psychological empowerment (meaning, competence, effectiveness, autonomy, trust) human resources and empowering relationship with the effects of productivity (construction, reducing time, increasing the quantity, quality improvement), model conceptual study are presented blow.

- Clear Goals
- Access to information
- Based remuneration
- Modeling
- Organizational support
- Access to resources
- In-service resources
- Provide feedback

\section{Research method}

The aim of this study is an applied research because its outcome obtain empowering human resources in the field of ICT research is in line with productivity effects. Based on how to obtain the required data, the present study is a correlational research because with the help of a questionnaire to gather detailed information and real phenomenon and cause and effect relationships between related components empowerment has studied the phenomenon.

\section{Procedure for research}

In this study, using quantitative methodology, the relationship between individual and organizational dimensions of empowerment were examined. They relate to the empowerment of exploratory mixed method was used. In mixed exploratory research project, the researchers is that the basic and accurate information about a phenomenon or uncertain status discovered. In mixed exploratory research project, researcher first through qualitative research methods to gather the required information. Qualitative data collection to countless aspects of phenomena are described. The initial recognition of the possibility about the phenomenon under study provides. After this stage researchers to test theories developed, can be obtained using quantitative obtained from the qualitative phase accreditation and the factors that have little effect, modify, alter or remove. Therefore, in the second study to evaluate the aspects relates $\backslash \mathrm{d}$ to environmental factors and Technology and their relationship with empowerment and qualitative methods were used to validate the data obtained from the qualitative, methods were used.

\section{Population and sample}

The sample included all human resources (employees and managers) institute of communications and information Technology and the qualitative phase consisted of experts (executives and experts from scientific and academic research), respectively. The reason of this population need to achieve the main goal of the research, aspects related to human resources empowerment institute of communication and information Technology, and access to them according to the territory where research was a researcher. 
The sampling method used in the study was the first study simple random sampling and the sample size in this study was 224 .

In the second study, the mixed methods was used because the sampling strategy, a combination of qualitative and quantitative sampling technique and in particular, mixed sequential sampling methods was used. Therefore in the second study, in order to carry out qualitative research of purposive sampling (snowball sampling) and quantitative research (as in the first study) of simple random sampling methods was used. The sample size in qualitative research phase were selected 15 experts, of whom five were among 10people among the scientific and academic experts, managers and consultants were the institute of communications and information Technology. A sample of the qualitative phase as well as the first study, 224 people patients were determined.

\section{Data collection}

In this study, to collect scientific literature on the subject of research, library and records were used. The data included the institute of communication and information Technology staff comments on each of the factors (individual organizational environmental and Technological) affecting empowerment as well as features and demographic them. The data from the study mentioned specifically institute survey of employees by two separate questionnaires were used.

Experts' detailed qualitative phase data include comments and responses to questions about the research is that data from the study specifically mentioned semi-structured interviews were used. In this type of interview, questionnaire and they were full and conclusive of question is not and predetermined and what should be done with the help of a checklist.

\section{Measures}

To measure the dimensions of psychological empowerment (meaning, competence, efficiency, autonomy trust) Spritzer the questionnaire (1995) and to assess the effects of productivity (cost reduction, reducing time, increasing the quantity, quality improvement), personal factors (selfesteem, responsibility, creativity, internal locus of control) and organizational (on the objectives, access to information remuneration based on performance, modeling, organizational support, assess to resources, training, provide feedback) a questionnaire was used.

\section{Results}

Examine the relationship between demographic factors and organizational factors in empowerment. The results of spearman correlation test to examine the relationship between demographic factors and psychological empowerment and organizational nature and enabling factors were identified for the table.

Table1

The relationship between demographic factors and organizational factors and empowerment

\begin{tabular}{|l|l|c|c|c|}
\hline \multirow{4}{*}{ Personal factors } & & $\mathrm{r}$ & Sig. & \\
\cline { 2 - 5 } & Self-esteem & 0.236 & 0.000 & Meaningful connection \\
& responsibility & $0 / 100$ & $0 / 136$ & No meaningful connection \\
& creativity & $0 / 259$ & $0 / 000$ & Meaningful connection \\
& Internal locus of control & $0 / 330$ & $0 / 000$ & Meaningful connection \\
\hline Organizational & Clear goals & $0 / 335$ & $0 / 000$ & Meaningful connection \\
factors nature & Access to information & $0 / 246$ & $0 / 000$ & Meaningful connection \\
\hline
\end{tabular}




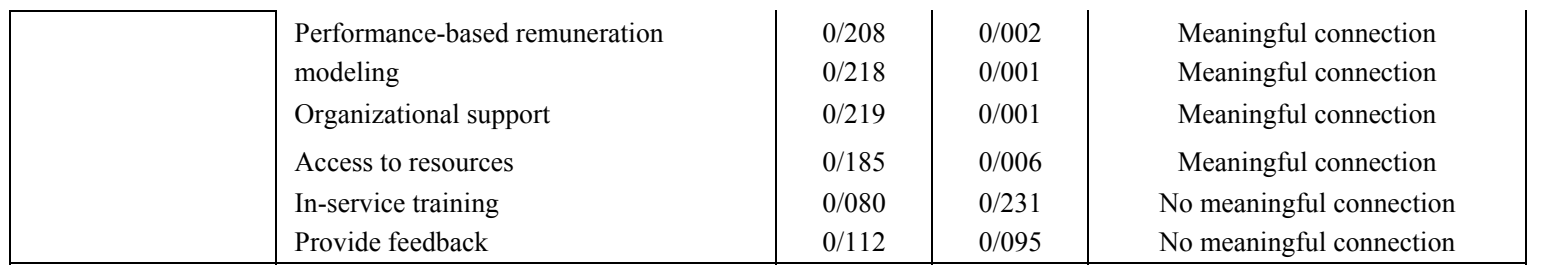

According to the results of spearman correlation test, because the amount obtained significant number of officials $(0 / 136)$ higher than standard significance level $(a=0 / 05)$ the relationship between these variable and psychological empowerment cannot be confirmed. But a significant number are obtained from other individual factors, including confidence $(0 / 000)$, creativity (0/000) and internal locus of control (0/000), less than the standard significance level $(a=0 / 05)$ is. The relationship between these factors and psychological empowerment is confirmed. According to the correlation coefficient for these factors in the results table, the correlation between psychological empowerment and self-esteem factors variable 0/236, creativity $0 / 259$, and internal locus of control is $0 / 330$.

Also according to the results of spearman correlation test, because a significant number value obtained for both in-service training (0/236) and provide feedback (0/095) higher than standard significance level $(\mathrm{a}=0 / 05)$ is. The relationship between these two variables are not licensed and psychological empowerment. But a significant number obtained for the factors, the nature of the organization (including: clarity of goals $0 / 000$, access to information $0 / 000$, performance- based remuneratelion, modeling 0/001 and organizational support $0 / 001$, access to resources 0/006) less than standard significance level $(a=0 / 05)$. Thus, the relationship between these factors and psychological empowerment is confirmed. According to the correlation coefficient for these factors in the results table, the correlation between psychological empowerment variables with clear operating objectives $0 / 335$, information access $0 / 246$, performance-based remuneration $0 / 20$, modeling $0 / 218$, organizational support $0 / 185$ and access to resources is $0 / 219$.

A) The link between empowerment and productivity effects to investigate the relationship between empowerment and productivity aspects of human resources in the institute of communications and information Technology, spearman rank correlation test used table (2).spearman correlation analysis to examine the relationship between the dimension of empowerment and productivity effects.

Table2- The relationship between the dimension of empowerment and productivity effects

\begin{tabular}{|c|cc|c|}
\hline \multirow{2}{*}{ variable } & \multicolumn{2}{|c|}{$\begin{array}{c}\text { Psychological empowerment } \\
\text { correlation }\end{array}$} & Sig. \\
\hline Meaningful & 0,427 & 0.00 & Significant \\
competence & 0,468 & 0.00 & Significant \\
effects & 0,503 & 0.00 & Significant \\
autonomy & 0,621 & 0.00 & Significant \\
trust & 0,313 & 0.00 & Significant \\
Psychological empowerment & 0,652 & 0.00 & Significant \\
\hline
\end{tabular}

According to the spearman correlation test results, obtained significant value for all subdimension of empowerment (meaningfulness, $0 / 000$, competence $0 / 000$, effectiveness $0 / 000$, 
autonomy $0 / 000$ and trust $0 / 000)$ less than the standard significance level $(a=0 / 05)$. Thus, but the relations between all sub-dimension of psychological empowerment and productivity effects is confirmed. According to the correlation coefficient for the mentioned aspects in the results table. The correlation between productivity variable effects with significant lateral dimensioned $0 / 427$, competence 08468 , effectiveness $0 / 503$, autonomy $0 / 621$, and the trust is $0 / 313$. On the other hand, a significant number value obtained for the main dimensions of psychological empowerment $(0 / 000)$ less than the standard significance level $(a=0 / 05)$ is. So the connection between psychological empowerment and productivity effects is confirmed.

Given the correlation obtained in the results table, the correlation between variables in productivity effects and psychological empowerment is $0 / 652$.

\section{Conclusion}

The desirable model (relationship between individual and organizational nature empowerment in line with productivity effects) by both sizing the theoretical relationship between each individual and organizational factors associated with empowerment and of the effects of productivity were developed. In other words the structure of the model includes variables such as the nature of the organization, empowerment and productivity aspects and the questions related to each variable in the model parameter for the relationship between these structure titles paths questionnaire model. The relationship between individual and organizational factors and psychological empowerment of human resources in the institute of communications and information Technology, using simple linear regression analysis showed that:

- The relationship between psychological empowerment responsibility and not licensed, but the relationship between self-esteem creativity and internal locus of control with psychological empowerment is confirmed. Due to the beta value obtained for the above mentioned factors in the regression analysis, the influence of psychological empowerment variable self-esteem factor $0 / 190$, creativity and internal locus of control is $0 / 275$.

- After the organizational nature of the relations between all the factors (including: clarity goals, access to information, bonuses, modeling, organizational support access to resources, training and provide feedback) and psychological empowerment is confirmed. Due to the beta value obtained for the above mentioned factors in the regression, analysis, the influence of psychological empowerment of clarity of goals $0 / 319$, access to information $0 / 258$, performance-based bonuses $0 / 271$, modeling $0 / 264$, organizational support $0 / 264$, access to resources $0 / 214$, training is $0 / 150$ and provide feedback is $0 / 140$.

A) the relationship between empowerment and productivity effects the relationship between psychological empowerment and productivity aspects of human resources in the institute of communications and information Technology, using simple linear regression analysis showed that:

- Relations between all sub- empowerment dimensions (including: significance, suitability, effectiveness, autonomy and trust) the effects of productivity is confirmed. 
Due to the beta value obtained for the mentioned aspects in regression analysis, the variables influence the productivity of the significant aspects of $0 / 149$, competence $0 / 116$, autonomy is $0 / 213$ and trust is $0 / 165$.

- The relationship between the main dimensions of psychological empowerment effects of productivity effects of psychological empowerment is $0 / 618$.

Since the results showed that the effects of psychological empowerment is affecting employee productivity, therefore, institute communication and information Technology manager, should be the subject of special attention and their empowerment in the field of human resources and its human resources strategy based on promoting empowerment of their staff for this purpose should review all activities related to human resources management or variations exist. Since the relationship between individual characteristics such as self-esteem, creativity and internal locus of control was confirmed with psychological empowerment.

Managers, in addition to other current requirements for applicants to the above characteristics, special importance will be attached.

And standard tools to assess each of these factors in the selection process and attract, develop them. Also, one of the requirements and standard organization promoting individuals based on characteristics of these formation. In addition, it is necessary to promote creativity and self-esteem level of current staff, with regular educational programs and targeted and continuous action. Due to the confirm the effects creativity and innovation by making the bed and sufficient space and time for the development of creativity and innovation as well as encouraging employees to practice their efforts.

According to verity the nature of the relationship between organizational factors (including: clarity of goals, access to information, bonuses, performance- based logistics, modeling, organizational support, access to resources), it is recommended that all managers factors into reality. In this regard, the following actions are recommended:

According to the confirmed positive relationship between employees empowerment of clarity of goals, recommended personal, organizational goals correctly states, the goal of the organization and planning and policy so that the objectives realized, coordinated and are obtained.

According to the confirmed positive relationship between access to information and access to resources, employee empowerment, recommended administrator to create organization information necessary to performance tasks to them and to guide people towards appropriate and timely decisions and to act responsibly in organizational activities they should be about organizational performance, mission, program, goals, funding and in general what is going on awareness and information specifically. The facilities provide suitable work for employees and sorting the option to provide information and resources on goals should be revised so that there is not enough staff in the absence of external disposal is responsible not know.

According to confirmed positive relationship with performance-based variable remuneration is recommended empowerment, managers motivate staff to raise the level and appropriate and faire reward system based on performance and merit to operate and promote people based on their competence and their ability. The reward creativity, imagination individual and collective needs and individual interests' individual difference rewards the attention. 
Due to the variable modeling confirmed a positive relationship empowerment, recommended by establishing successful working patterns and behavior of individual and units, encourage new ideas and unique work and information the success for all employee, encouraging them to take similar behaviors and activities.

According to confirmed a positive relationship between teamwork and empowerment, and administrators need to place emphasis on the traditional hierarchy set up working teams and its employees a series of autonomous work teams organize. The teams have full responsibility for the planning and management process.

According to confirmed positive relationship between organization support and confidence of management with empowerment, recommended managers to create an atmosphere of sympathy and trust in the organization and in addition to their support for the actions and ideas of employees and facilitate organizational barriers, other are also encourage to established their networks support each other.

\section{References}

Azar, A., Momeni, M. (1383). statistics and their application in management. ,1 \& 2, ( $8^{\text {th }}$ ed.). Tehran: press side.

Dehaghani, Z. A., \& Abbasi, M. (2014). The study of relationship between Pigmaliyon factors and personnel's performance of the administration of health insurance in Isfahan and Chaharmahale Bakhtiyari provinces according to Rozental four factor theory.

Dong, Y., Liao, H., Chuang, A., Zhou, J., \& Campbell, E. M. (2015). Fostering employee service creativity: Joint effects of customer empowering behaviors and supervisory empowering leadership. Journal of Applied Psychology, 100(5), 1364.

Goetsch, D. L., \& Davis, S. B. (2014). Quality management for organizational excellence. Upper Saddle River, NJ: pearson.

Humborstad, S. I. W., \& Perry, C. (2011). Employee empowerment, job satisfaction and organizational commitment: An indepth empirical investigation. Chinese Management Studies, 5, 325-344.

Ibrahim, M. (2015). Paradigm of employee's empowerment: proposal for business actors in Aceh Province. European Journal of Research and Reflection in Management Sciences, 3(3).

Jahanian, R. (2014). Human Resources Empowerment. International Journal of Management Sciences, 3, 548-558.

Jahanian, R. (2014). Human Resources Empowerment. International Journal of Management Sciences, 3(8), 548-558.

Kakar, P., Raziq, A. \& Khan, F. (2015). Impact of Human Resource Management Practices on Employee Retention: A Case of Banking Sector in Quetta Baluchistan. Journal of Management Info, 5.

Law, R., Buhalis, D., \& Cobanoglu, C. (2014). Progress on information and communication technologies in hospitality and tourism. International Journal of Contemporary Hospitality Management, 26(5), 727-750.

Madison, D., \& Denise, R. (2015). Empowering Employees through Networking and Mentoring.

Pando-Garcia, J., Periañez-Cañadillas, I. \& Charterina, J. (2016). Business simulation games with and without supervision: An analysis based on the TAM model. Journal of Business Research, 69, 1731-1736.

Podsakoff, P. M., MacKenzie, S. B., \& Podsakoff, N. P. (2016). Recommendations for creating better concept definitions in the organizational, behavioral, and social sciences. Organizational Research Methods, 19(2), 159-203.

Scat, S., Zhafe, D. (1379). Enabling employees translated by Mehdi Irinnejad Parizi, Research and Training institute of management.

Shih, H. P., Lai, K. H., \& Cheng, T. C. E. (2015). A Dual-Process Model to Assess User Attitudes and the Likelihood of Electronic Word-Of-Mouth Adoption. In PACIS (p. 226).

Tallon, P.P., \& Pinsonneault, A. (2011). Competing perspectives on the link between strategic information technology alignment and organizational agility: insights from a mediation model. Mis Quarterly, 463-486.

Tschannen-Moran, M., \& Gareis, C. R. (2015). Principals, trust, and cultivating vibrant schools. Societies, 5(2), 256-276.

Yazdani, B. Yaghoubi, N., \& Giri, E. S. p. (2011). Factors affecting the Empowerment of Employees. European Journal of Social Sciences, 20, 267-274. 